\title{
RESPUESTA A PÉREZ LUÑO, ATIENZA Y RUIZ MANERO
}

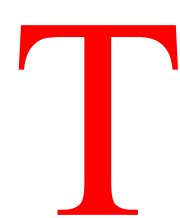
anto las acotaciones de Antonio-Enrique Pérez Luño como los problemas que señalan Manuel Atienza y Juan Ruiz Manero me obligan a precisar algunos puntos, reformular ideas y ampliar ciertos temas de mi trabajo sobre el concepto de derechos humanos. Les agradezco vivamente el interés y la minuciosidad con que lo han leído. Si en algo mejora con esta respuesta sólo a sus observaciones será debido.

Pérez Luño termina sus acotaciones con una invitación a aceptar, de la mano de Miguel de Unamuno, una teoría consensual de la verdad. Es una invitación que en principio me siento inclinado a aceptar, aunque debo llamar la atención sobre lo escasamente autorizado que se halla don Miguel para hacer semejante propuesta. Disentir, y no tanto consentir verdades, fue siempre la impronta básica de su vida intelectual. Y escrutarlas: «inquirir verdades y decirlas», ése era para él el «santo oficio» del escritor. Mucho peor dotado que don Miguel, pero algo deudor suyo, lo que me propongo con mi trabajo es, precisamente, tomar la idea convencional, convenida, consentida de «derechos humanos», «inquirirla» y poner de manifiesto, a través de un análisis crítico, algunas dificultades internas que puede llevar consigo.

En particular llego a dos conclusiones provisionales: a) Si definimos la noción de «tener un derecho» en términos de que otro u otros tengan un deber u obligación, entonces el lenguaje de los derechos es redundante y nos vemos obligados además a atribuir una prioridad lógica y axiológica a los deberes u obligaciones sobre los derechos. Como esta implicación me parece indeseable trato de reformular la noción de «tener derecho» en otros términos, con el fin, entre otros, de no poner en peligro la prioridad, sobre todo axiológica, de los derechos humanos. b) Si definimos, como es verdad convencional, los derechos humanos como derechos universales, "prima facie» e inalienables, entonces estamos haciendo referencia a proposiciones de una gran fuerza prescriptiva y ello no parece compadecerse bien con una incesante ampliación del catálogo de los mismos sin que acabemos por encontrarnos sumidos en severos dilemas teóricos y prácticos. En mi trabajo trato solamente de llamar la atención sobre ello con el fin de que dediquemos algo de nuestro tiempo a pensar en estos posibles dilemas.

Al hilo de esas conclusiones provisionales trataré de responder y comentar las observaciones de mis colegas. Acepto que mi definición de la noción de «tener derecho...» pueda ser «explicativa» en los términos que menciona Pérez Luño, pero sólo pretende eludir la implicación de redundancia a que he aludido; no apetecen mayores dosis de autoridad. Respecto a la definición de «derechos humanos» creo que más bien trato de llevar a cabo un análisis de las implicaciones de una definición lexical 
o lexicográfica muy usual y que tácitamente hago también mía. Para llegar a ambas tengo que abrir primero la cuestión de si los derechos son definibles en términos de modalidades deónticas típicas y postulo que no lo son. Desgraciadamente utilizo un término infeliz, «parafrasear», para expresar la posible interdefinibilidad entre «derecho» $\mathrm{y}$ «deber» dados dos actores, y Atienza y Ruiz Manero me llaman justamente la atención al respecto. Sin embargo no parecen ser críticos con la tesis principal, a saber: que mediante expresiones deónticas típicas no se puede agotar la significación de «tener un derecho».

Pero yo doy un paso más allá: propongo que no sólo las normas de conducta típicas (enunciados deónticos) sino tampoco las normas de competencia son capaces de agotar esa significación porque tanto las unas como las otras son «técnicas normativas de protección de derechos» más que derechos. Los derechos serían algo que estuviera más allá de las normas y constituyera la razón para articular esa protección mediante las normas. Y aquí, seguramente por mis propias dudas y mis infelices expresiones, empiezan a producirse desacuerdos aparentemente más serios. Porque puede quizás pensarse que lo que afirmo es que «más allá» del sistema normativo jurídico se dan unos derechos jurídicos que constituyen la razón justificatoria de normas de ese sistema. Y no se trata de eso.

Mi posición es que cualquier sistema normativo dotado de una cierta complejidad (sea jurídico, moral, social, de juegos, etc...) se presenta como un conjunto dentro del cual pueden hallarse elementos de muy diversa naturaleza, tales como normas (de conducta y de competencia), principios, descripciones, juicios de valor, definiciones, reglas técnicas, etc... Tales elementos están, permítaseme que insista, dentro del sistema normativo en cuestión, y se hallan relacionados entre sí por vínculos de muy diverso tipo. Uno de esos vínculos puede ser de naturaleza argumentativa práctica, de forma que unos elementos del sistema sean razones prácticas para la existencia de otros elementos del sistema. Y sostengo que para comprender qué es un derecho no puede uno limitarse a contemplar sólo las normas del sistema, sino que hay que ir «más allá» a la búsqueda de algunos de los otros componentes del mismo y de algunos de los vínculos que los interrelacionan, porque los derechos son miembros complejos de dichos sistemas. No creo que esto sea «confundir los derechos con el fundamento de los derechos» como afirman Atienza y Ruiz Manero porque, entre otras cosas, los derechos se presentan como razones intrasistemáticas de normas de conducta y de competencia, y el fundamento de un derecho sería más bien la justificación extrasistemática de sus componentes. A este respecto sugieren también ambos que puede producirse un sinsentido al calificar de p.e., inalienables a las 'razones' y no a los derechos. Sería en todo caso el mismo sinsentido que se produjera al calificar como 'posible' a una 'razón' cuando digo: «Que es posible que llueva es una razón para llevar paraguas». Lo que es posible no es la razón sino el hecho de que llueva. Lo que es 'inalienable' no es la razón sino el estado de cosas 'bueno' que suministra esa razón.

Si estas cosas quedan claras creo que el núcleo de las acotaciones de Pérez Luño se viene abajo, y ello porque creo advertir que ha leído mi trabajo con la mirada usual del prejuicio «legalista». Trataré de explicar 
esto. Los sistemas jurídicos modernos son particularmente complejos y minuciosos y como, por su propia naturaleza de «jurídicos», administran el uso de la fuerza, sus normas se ven con frecuencia satisfechas a través de un mecanismo especializado de «forzamiento». Muchas veces los sistemas jurídicos protegen los derechos que confieren mediante la técnica de poner en manos del titular la posibilidad de poner en marcha dicho mecanismo de «forzamiento», y ha sido seguramente la eficacia y la perentoriedad de dicha técnica de protección lo que ha acabado por llevar a muchos a sostener que sólo puede hablarse de «tener un derecho» cuando se puede poner en marcha el dispositivo institucional de la coacción. Pero esto no se corresponde con la realidad ¡ni siquiera en el ámbito del sistema jurídico mismo!

Para desterrar ese prejuicio hay que aceptar que del mismo modo que en el sistema jurídico al lado de las obligaciones encontramos derechos legales, en ese conjunto de proposiciones que llamamos moral o moralidad, si tiene la complejidad que hoy tiene, al lado de las obligaciones morales encontramos derechos morales. Y por lo mismo que las obligaciones o deberes morales no tienen una conexión necesaria con las obligaciones o deberes legales, los derechos morales no la tienen tampoco con los derechos legales. Es decir, el hecho de que algo sea obligatorio moralmente no implica que sea obligatorio legalmente; y que alguien tenga un derecho moral no implica que tenga un derecho legal. Y al revés las cosas suceden exactamente igual: las obligaciones legales no tienen por qué ser necesariamente obligaciones morales, y los derechos legales no tienen por qué ser derechos morales. De forma que puede utilizarse la noción de 'derechos morales' sin que eso suponga «vehículo de intersección entre el Derecho y la Moral», como afirma Pérez Luño; y por mi parte sigo manteniendo que entre Derecho y Moral no hay conexiones necesarias o conceptuales, aunque pueda haberlas históricas y contingentes.

Pues bien, si concebimos el iusnaturalismo como una teoría del derecho que afirma que al lado (o por encima, o más allá...) del orden jurídico empírico hay otro orden normativo también jurídico, más o menos extenso, y con el que aquél mantiene o debe mantener determinadas relaciones, entonces resultará claro que mi posición no es iusnaturalista. Cuando Kelsen critica al iusnaturalismo como «Dualismo en la teoría del derecho», lo que niega es que lo jurídico se presente en la realidad en dos manifestaciones distintas: lo jurídico-natural y lo jurídico-positivo. Pero no niega que por un lado se dé un orden jurídico y por otro una moralidad, y no niega, por cierto, tampoco, que por un lado haya 'derechos jurídicos' y por otro 'derechos morales'. Esa es mi posición.

$\mathrm{Y}$ vamos al centro de la cuestión. Si aceptamos que tenemos el orden jurídico empírico (nacional o internacional) por un lado, y la moralidad por otro, y que tenemos en el primero, derechos legales y en la segunda, derechos morales, ¿dónde situamos los «derechos humanos»? Si los situamos en el orden jurídico positivo como derechos legales nos vemos en la tesitura de tener que afirmar que sólo tienen «derechos humanos» aquellos seres humanos que son destinatarios de las normas y demás 
elementos de ciertos sistemas jurídicos empíricos. Y, entonces, a la pregunta ingenua ¿viola el régimen de Pinochet los derechos humanos?, tenemos que contestar: NO, porque los chilenos no tienen derechos humanos (o no tienen ciertos derechos humanos). ¿Violaba el régimen de Franco los derechos humanos? No, porque hasta 1978 los españoles no tuvieron derechos humanos. Es cierto que podemos apelar a la Declaración «Universal» de las Naciones Unidas, pero las salidas son tan poco convincentes como éstas: el nazismo, que es anterior a esa declaración, no violó, por lo visto, los derechos humanos.

Esto no sólo me insatisface personalmente sino que me parece contrario a la más elemental semántica de la expresión 'derechos humanos'. Siempre se ha dicho que la condición de «ser humano» era lo único que se necesitaba para ser titular de 'derechos humanos' y creo, por mi parte, que en Chile se violan y en la Alemania nazi se violaron gravemente los derechos humanos, fuera cual fuera el sistema jurídico-positivo imperante. Pues bien, el único camino para conferir un significado libre de aporías a estas ideas es mantener que tales derechos son derechos morales, de forma tal que los sistemas jurídicos que no los reconozcan traicionan exigencias morales de gran importancia y violan derechos. Esas exigencias o pautas morales, esos derechos morales, son tales que su desconocimiento justifica acciones como la desobediencia a las leyes y la resistencia a la opresión jurídico-positiva. Y en este sentido la voz de Antígona sigue teniendo el vigor de siempre.

Dando por sentado que los derechos humanos son derechos morales y no pueden ser otra cosa mi argumentación es hipotética: $S i$ se mantiene que los derechos humanos son derechos universales, derechos moralmente muy fuertes y derechos inalienables, entonces no podemos pensar que su nómina crece sin cesar al ritmo de los tiempos, y en particular no podemos arriesgarnos a suponer que se reproducen en «generaciones» con cierta rapidez, sin que se ponga gravemente en cuestión que son derechos fuertes y para todos sin excepción. Al menos no lo podemos pensar en un mundo escaso y superpoblado como el nuestro. Los derechos humanos, si son así, tienen que ser pocos para muchos y no muchos para pocos, y la teoría de las «generaciones» desemboca seguramente en esta segunda posibilidad.

Estoy seguro de que la preocupación de Pérez Luño por los problemas de los derechos humanos llamados de la «tercera generación» obedece a inquietantes realidades de nuestro tiempo que nadie con un mínimo de sensibilidad moral puede ignorar. De lo que no estoy tan seguro es de que se necesiten «nuevos» derechos humanos para hacer frente a esas realidades. Para expresarlo con una idea que, como tantas otras, he aprendido de Ernesto Garzón Valdés, creo que de las «viejas» premisas éticas se pueden seguir obteniendo conclusiones aptas para responder a los nuevos desafíos. No se trataría, por tanto, de nuevos derechos o de nuevas generaciones de derechos, sino de respuestas de las exigencias morales básicas ante nuevos interrogantes. Y esto no es una mera opción de preciosismo metodológico sino algo que puede determinar que dispongamos o no dispongamos de criterios para resolver los dilemas morales que han de presentarse. Porque si concebimos cada respuesta a un 
nuevo problema como el nacimiento de un derecho fundamental que, como tal, tendrá la fuerza y la perentoriedad de todos los derechos fundamentales, las contradicciones entre demandas morales fuertes serán incesantes y, con cierta facilidad, insolubles. Si, en cambio, concebimos esa respuesta como la articulación de un nuevo alcance para un postulado ético anterior, como una nueva «conclusión» o como un «derecho derivado», para seguir la terminología de Raz, estaremos en mejores condiciones para diseñar racionalmente el territorio y los límites de los derechos básicos en cada momento histórico. Mi desacuerdo con Pérez Luño no es tampoco en este caso, como se ve, insalvable. El tema, que sugieren Atienza y Ruiz Manero, de los posibles moradores del universo de los derechos humanos, es lo suficientemente amplio y complejo como para declinar cortésmente su invitación a abordarlo aquí.

Quiero, por último, hacer por mi parte algunas acotaciones a las acotaciones finales de Pérez Luño en la esperanza de que sirvan para iluminar un poco más las cuestiones dada la relevancia de los temas que suscita. En primer lugar unos comentarios sobre la función de la «historia» y de las concepciones de la historia en la teoría de los derechos humanos. Todo surge en torno a la idea de que el rasgo de «universalidad» que es inherente a la semántica de los derechos humanos, nos obliga a poner atención en aspectos del ser humano no especialmente determinados por circunstancias empíricas o por rasgos contingentes. Esa «descontextualización» parece que aleja mi propuesta de la historia $\mathrm{y}$, en definitiva, de la realidad. Después de las consideraciones anteriores no creo que esto pueda mantenerse pero me da pie para cuestionar precisamente el papel de la «historia» como presunto artífice de los derechos humanos, que son, según Pérez Luño, una «categoría histórica». ¿Qué quiere esto decir? Si lo que quiere decir es que la idea de derechos humanos «aparece» y se desarrolla en la historia no tengo nada que objetar, sencillamente porque todo aparece, se desarrolla (si es que se desarrolla) y desaparece en la historia. También la más abstracta de las especulaciones racionales. Si lo que quiere decir, más bien, es que se trata de una categoría que aparece en un determinado momento histórico como consecuencia de ciertos problemas que provocan un desarrollo de la conciencia moral o jurídica que, al descubrir, por ejemplo, la individualidad humana como centro de imputación ética o agencia moral o jurídica, necesita de un nuevo instrumental conceptual para dar cuenta de sus nuevas percepciones y resolver los nuevos problemas, tampoco tengo nada que objetar. Esto constituye la explicación genética de la categoría, aunque he de advertir que no es privativo de ella pues todas las categorías científicas y culturales, incluso el cálculo infinitesimal o el álgebra de Boole, son categorías «históricas» en este sentido. Pero si lo que se sugiere con esa expresión es que la «historia» suministra una demostración o justificación de su validez científica o moral, entonces no puedo compartir semejante sugerencia. La validez de los enunciados se determina por argumentación racional, teórica y práctica, y el hecho de que se presenten en un momento histórico no añade nada a esa argumentación. La historia está llena de categorías erróneas. 
Y me parece advertir que algo de esa tercera posibilidad hay en la vinculación que establece Pérez Luño entre las concepciones optimistas o progresistas de la historia y la expansión de los derechos humanos, por una parte, y entre las concepciones pesimistas de la historia y la reducción de los derechos humanos por otra. En primer lugar tengo que decir que detecto en sus acotaciones una cierta contradicción, porque no sé cómo se puede tener una concepción "progresista» u optimista de la historia y temer al holocausto termonuclear o la degradación irreversible de la naturaleza tanto como para tratar de oponerles toda una generación de derechos humanos. Con una concepción optimista de la historia sobran todas esas cautelas, y también las de las «generaciones» anteriores de derechos. No habría más que sentarse en la carreta de la historia para asistir al progreso ineluctable. Porque no sé cómo puede sostenerse concepción alguna de la historia, ni pesimista ni optimista, y al mismo tiempo defender un conjunto de postulados morales. La ética es, por naturaleza, contrafáctica, y una de sus preguntas fundamentales: ¿qué debo hacer?, presupone conceptualmente la existencia de un abanico contingente de opciones, lo que convive dificultosamente con la inevitabilidad de la historia. Porque, por último, no veo cómo pueda mantenerse una concepción de la historia, que no sea una pura arbitrariedad, en ningún caso. La «historia» es un totum revolutum de acciones e interacciones, azares y causalidades, hechos y actitudes de cuyo decurso sólo podemos enterarnos (para nuestro beneficio o nuestro perjuicio) una vez que ha sucedido, es decir, «post festum», sin que en mi opinión pueda alcanzarse a vislumbrar hoy por hoy la más remota posibilidad intelectual de hacer significativas y razonables conjeturas prospectivas hacia el futuro. No hay pues concepción alguna de la historia que se tenga mínimamente en pie, y decir de su decurso que es un movimiento «dialéctico» me parece, con todo respeto, un artificio cultista para traducir aquello de «si sale con barba San Antón y si no la Purísima Concepción», es decir, recurrir a un concepto a través del cual podemos explicar lo bueno y lo malo, el avance y el retroceso, la paz y la guerra, o lo que es lo mismo, podemos explicarlo y comprenderlo todo, y como dijo también don Miguel de Unamuno, comprenderlo todo es, en puridad, no comprender nada. Pero si la historia es un río inmenso y tumultuoso de problemas y soluciones, errores y aciertos, momentos sublimes e inmundicias morales, entonces el hecho de que algo venga flotando en ese río no justifica en absoluto su calidad científica o ética. Tenemos que usar un conjunto de criterios para diferenciar las soluciones buenas de las malas, los errores de los aciertos, los momentos de excelencia moral de las inmundicias éticas,... los derechos humanos del Terror o la guillotina que flotan a su lado. Y son esos criterios los que, en su caso, suministran un respaldo de validez científica o ética al conjunto de nuestras creencias, y no la historia ni nuestra concepción de la historia. A riesgo de suscitar otro debate ajeno a éste me atrevería incluso a decir que uno de los factores que nos pueden llevar al holocausto nuclear es, precisamente, la concepción optimista o «progresista» de la historia, y también, por qué no decirlo, la concepción religiosa de «esta» vida, providencia, y la «otra» 
recompensa. Porque si tuviéramos perfectamente claro que la historia empírica es la única que tenemos y corre sólo de nuestra cuenta la conciencia antinuclear sería mucho más viva y eficaz.

Para terminar quisiera poner brevemente de manifiesto, las dudas que albergo respecto de la creencia de Pérez Luño en torno a lo que, según él, es una «consecuencia práctica» equivocada de mi posición sobre los derechos humanos. Me refiero al hecho, que parece a primera vista indudable, de que aquellos Estados donde más se reconocen los derechos humanos es donde más protección real y efectiva garantía de los mismos se puede constatar. Pero, pregunto, ¿los derechos humanos de quién? Y la respuesta tácita no puede ser más que una: los derechos humanos «de sus propios ciudadanos». Estamos, pues, ante un panorama en el que hay Estados en los que ese descubrimiento de «nuevas necesidades» de que habla Pérez Luño marcha tan rápidamente que está llegando a alcanzar cotas de auténtica sofisticación colectiva y cada día se «necesitan» cosas más superfluas y perecederas; exactamente los mismos Estados donde surgen como «derechos humanos» los derechos de «los consumidores» la «protección de datos»y la «calidad de vida», para satisfacer y proteger los cuales se hacen cosas tales como destruir literalmente, o congelar en stocks interminables, millones de toneladas de alimentos o bienes de primera necesidad con el único objetivo de «mantener los precios» o no poner en peligro el status de sectores «de sus propios ciudadanos» (o de parte de ellos). Mientras tanto la muerte por hambre o la vida en los límites de la pura supervivencia es la realidad cotidiana de una buena porción de la especie humana. Pues bien, si alguien piensa que los derechos humanos como categoría moral son universales tiene que preguntarse si las mayores y más usuales violaciones de los derechos, tan usuales que ni siquiera las advertirnos ya, no se estarán produciendo precisamente en aquellos Estados en los que, con las fronteras bien cerradas y sin dignarse a mirar por encima de ellas, no sólo se tiene «derecho humano» a alimentarse, sino también a la calidad y el buen empaquetado de los alimentos, no sólo se tiene «derecho humano» a la salud, sino también a elegir el médico más congruente con nuestro carácter, no sólo se tiene «derecho humano» a la educación, sino también a una amplia panoplia de ofertas ideales y morales al gusto de cada unidad familiar. Y así sucesivamente. No trato de sugerir que esta «opulencia» en el disfrute de los derechos sea la causa directa de aquella otra miseria, pero tampoco cabe olvidar que la protección efectiva de muchos de esos minuciosos y sofisticados «derechos humanos» se lleva a cabo sobre la base de una cantidad de recursos económicos y sociales muy considerable. Y ello me lleva a temer que desde los «otros» Estados, los «otros» ciudadanos miren a los derechos del hombre como un artículo de lujo que, como siempre, sólo pueden disfrutar en lugares remotos. Si para tener dignidad moral hay que tener fortuna geopolítica de nacimiento, los derechos humanos serán ignorados.

\section{DOXA 4 (1987)}

